\title{
Welcome to Our New Publisher: Cambridge University Press
}

Suzanne F. Bradley, M.D.

After an extensive search and interview process involving 8 major publishers, Cambridge University Press emerged as the clear choice of the Society for Healthcare Epidemiology of America (SHEA) Board of Directors and Infection Control \& Hospital Epidemiology (ICHE) Journal Editors.

Founded by King Henry VIII of England in 1584, Cambridge University Press is the oldest publishing house in the world. As part of the University of Cambridge, United Kingdom, the University Press helps further the University's academic mission through the global dissemination of research and scientific knowledge. Recently, Cambridge was charged with extending its reach in to the areas of public health, epidemiology, and infectious diseases. With more than 50 offices and agents located in more than 50 countries on four continents, Cambridge is well positioned to meet that challenge. The Journals Division is home to more than 350 research journals primarily sponsored by scientific and professional societies.

Cambridge's long history of commitment to academic excellence, its mutual interest in public health and the prevention and control of infectious diseases, and its global presence were the main attributes that made a partnership with our Society and its Journal so attractive. Processes are already in place to increase the number of libraries, institutions, and individual subscribers who receive ICHE and to promote the visibility of Journal and the influence of SHEA.

So, as a result of this union, what changes in ICHE can readers expect to see? The most obvious change is the format for the ICHE cover and website that will recognize those individuals who greatly influenced the fields of infection control. New applications will allow readers to access the journal content irrespective of platform or type of electronic device. In addition, for the first time, the acronym "ICHE" that has been in use informally for many years will be recognized in association with the Journal title. Using the ICHE website at Cambridge Journals Online, readers will be able to download slides of tables and figures as well as high-quality color images from each article. Supplemental materials provided by the authors will also be made available online. Authors will benefit from improved ways to search for content and will be able to maintain those personalized searches online. Readers will also have access to virtual collections of papers such as "Most Cited Articles" or "Past SHEA Award Recipients." Since the Press owns and operates Cambridge Journals Online, we will have the ability to modify the website in a timely fashion to meet readers' needs.

What changes in the day-to-day operations of ICHE will authors see? Cambridge has already been in charge of submissions since September 1, 2014. Cambridge and University of Chicago Press have worked very closely and collegially in ensuring that the transition has been seamless. So seamless in fact, that I anticipate that most authors won't have recognized that a transition has even taken place. As part of our agreements with Cambridge, there are assurances in place that a high quality of copy editing and production standards will be maintained. I am confident that our new team including Aaron Johnson (Senior Editor), Meighan Schreiber (Managing Editor), Kelly Loftus (Production Editor), and Joon Won Moon (Journals Marketing Manager) will help us maintain the high standards that our readers have come to expect from ICHE.

Dr. Bradley is Editor-in-Chief of Infection Control \& Hospital Epidemiology and is Professor of Internal Medicine, Division of Infectious Diseases, University of Michigan Medical School, and Program Director, Infection Control, Veterans Affairs Ann Arbor Healthcare System, Ann Arbor, Michigan.

() 2014 by The Society for Healthcare Epidemiology of America. All rights reserved. 0899-823X/2015/3601-0001. DOI: 10.1017/ice.2014.35 